\title{
Montélimar, la Gondole
}

les Prés I et II

Frédéric Jallet

\section{(2) OpenEdition}

Journals

Édition électronique

URL : http://journals.openedition.org/adlfi/1606

ISSN : 2114-0502

Éditeur

Ministère de la culture

Référence électronique

Frédéric Jallet, « Montélimar, la Gondole », ADLFI. Archéologie de la France - Informations [En ligne], Rhône-Alpes, mis en ligne le 01 mars 2008, consulté le 19 avril 2019. URL : http:// journals.openedition.org/adlfi/1606

Ce document a été généré automatiquement le 19 avril 2019

(C) Ministère de la Culture et de la Communication, CNRS 


\title{
Montélimar, la Gondole
}

les Prés I et II

\author{
Frédéric Jallet
}

Identifiant de l'opération archéologique : 9899

Date de l'opération : 2008 (EX)

1 Le lieu-dit La Gondole se situe au nord de l'agglomération actuelle, à une altitude de 75 m NGF environ. Il s'appuie, à l'est, sur le pied du versant d'un massif qui culmine à $162 \mathrm{~m}$ NGF (Plateau des Chaberts). Au nord et à l'ouest, le site est ouvert sur la vallée du Rhône.

2 Les diagnostics n'ont livré aucun vestige archéologique à l'exception d'une fosse (bornage ?) (Les Près I) dont la position stratigraphique évoque un événement récent, postérieur au Moyen Âge.

3 Un des principaux acquis porte sur la mise en évidence d'une sédimentation tourbeuse dans la partie ouest de l'emprise (Les Prés I). Cette formation pourrait être rapprochée des observations réalisées précédemment plus au nord où un contexte comparable est daté vers 7100-6700 av. J.-C. (Roubion I de Brochier et al.1994). La présence de cette tourbe offre un potentiel pour l'identification des paléodynamiques naturelles et la restitution de l'évolution des paysages.

4 Un autre acquis concerne l'identification (J.-L. Brochier) d'un paléosol (Les Prés I et Les Prés II) marqué par des matières organiques où la malacofaune, au moins en partie terrestre, est abondante. Le mobilier archéologique qui en est issu est attribué au Néolithique final. Celui-ci (céramiques non tournées, industries sur silex, galets de calcaire et quartzite percutés et/ou chauffés) gît dans la couche et ne présente pas d'organisation. Il témoigne de la proximité d'une occupation, située entre 3500 et 2500 av. J.-C. Une présence humaine, située dans le même horizon chronologique, est identifiée à $500 \mathrm{~m}$ au sud-ouest (Ronco, Ferber, 2004).

5 Frédérique Jallet INRAP 
INDEX

Thèmes : paléosol, tourbière

Index géographique : Rhône-Alpes, Drôme (26), Montélimar

Index chronologique : Néolithique final

operation Expertise (EX)

\section{AUTEUR}

\section{FRÉDÉRIC JALLET}

INRAP 